\title{
Improving Drug-Therapy Decisions through Educational Outreach
}

\section{Citation}

Avorn, Jerry, and Stephen B. Soumerai. 1983. “Improving Drug-Therapy Decisions through Educational Outreach." New England Journal of Medicine 308 (24) (June 16): 1457-1463. doi:10.1056/nejm198306163082406.

\section{Published Version}

doi:10.1056/NEJM198306163082406

\section{Permanent link}

http://nrs.harvard.edu/urn-3:HUL.InstRepos:32696184

\section{Terms of Use}

This article was downloaded from Harvard University's DASH repository, and is made available under the terms and conditions applicable to Other Posted Material, as set forth at http:// nrs.harvard.edu/urn-3:HUL.InstRepos:dash.current.terms-of-use\#LAA

\section{Share Your Story}

The Harvard community has made this article openly available.

Please share how this access benefits you. Submit a story.

Accessibility 
subjects in the same age groups (unpublished data). The magnitude of the cholesterol-raising effect, which suggests at least a twofold increase in the risk of coronary heart disease, warrants further investigation.

\section{REFERENCES}

1. Dawber TR, Kannel WB, Gordon T. Colfec and cardiovascular discase: observations from the Framingham Study. N Engl J Med 1974: 291:871-4.

2. Heyden S, Tyroler HA, Heiss G, Hames CG, Bartel A. Coffec consumption and mortality: total mortality, stroke mortality, and coronary heart disease mortality. Arch Intern Med 1978: 138:1472-5.

3. Murray SS, Bjelke E. Gibson RW. Shunaan LM. Coffee consumption and mortality from ischemic heart disease and other causes: results from the Lutheran Brotherhood Study, 1966-1978. Am J Epidemiol 1981: 113: $661-7$.

4. Klatsky AL, Friedman GD. Siegelaub AB. Coffece drinking prior to acute myocardial infaretion: results from the Kaiser-Permanente epideniologic study of myocardial infarction. JAMA 1973; 226:540-3.

5. Wilhelmsen L. Tibblin G. Elmfeldt D. Wedel H. Werkö L. Coffec consumption and coronary heart disease in middle-aged Swedish men. Acta Med Scand 1977: 201:547-52.

6. Yano K, Rhoads GG, Kagan A. Coffec, alcohol and risk of coronary heart disease among Japanese men living in Hawaii. N Engl J Med 1977; 297: 405-9.

7. Thelle DS, Forde OH. Try K, Lehmann EH. The Tromsw Heart Study: methods and main results of the cross-sectional study. Acta Med Scand 1976: 200: $107-18$

8. Bjartveit K. loss OP. Gjervig T, Lund-Larsen P(3. The Cardiovascular Disease Study in Norwegian Counties: background and organization. Acta Med Sciand |Suppl| 1979: 634:1-70.

9. Dixen JW. Brown BM. BMIDP-79 Biemedical computer programs. P-series. Berkeley, Calif.: University of California Press. 1979.

10. Bjelke B. Colon eaneer and blood-cholesterol. Lanced 1974: 1:1116-7.

11. Little JA, Shanoff HM, Csima A. Yano R. Coffec and serum-lipids in coronary heart-discasse. Lancel 1960: 1:732-4.

12. Sacks FM. Castelli WP. Donner A. Kass H:H. Plasma lipids and lipoproteins in vegetarians and controls. N Engl J Med 1975: 292:1148-51.

13. Statistical yearbook of Norway. Oslo: Central Bureat of Statistics of Norway, 1981 .

14. Coffec drinking and acute myocardial infarction: report from the Boston Collaborative Drug Surveillance Program. Lancet 1972: 2:1278-81.

15. Jick H, Mettinen (SS. Neff RK. Shapiro S, Heinonen OP. Slone D. Coffec and myocardial infarction. N Engl J Med 1973; 289:63-7.

16. Rosenterg L. Slone D. Shapiro S, Katulman DW, Stolley PI), Miettinen OS. Coffece drinking and myocardial intarction in young women. Am J Epidemiol 1980: 111:675-81:

17. Rosenberg L.. Slone 1). Shapiro S, Kaufman WI). Miettinen OS. (asecontrol studies on the atcute effects of colfec upon the risk of myeciartial infaretion: problems in the selection of a hospital control series. Am J Finidemiol 1981: 113:646-52.

18. Hennekens CH, Drolette ML. Jesse MJ, Davies JF. Hutchison GiB. Coffec drinking and death due to coronary heart disease. N Engl J Med 1976: 294:63.3-6.

\title{
SPECIAL ARTICLE
}

\section{IMPROVING DRUG-THERAPY DECISIONS THROUGH EDUCATIONAL OUTREACH}

\section{A Randomized Controlled Trial of Academically Based "Detailing"}

\author{
Jerry Avorn, M.D., and StTiphen B. Soumerai, M.S.P.H.
}

\begin{abstract}
Improving precision and economy in the prescribing of drugs is a goal whose importance has increased with the proliferation of new and potent agents and with growing economic pressures to contain healthcare costs. We implemented an office-based physician education program to reduce the excessive use of three drug groups: cerebral and peripheral vasodilators, an oral cephalosporin, and propoxyphene. A four-state sample of 435 prescribers of these drugs was identified through Medicaid records and randomly assigned to one of three groups. Physicians who were offered personal educational visits by clinical pharmacists along with a series of mailed "unadvertisements" reduced their pre-
\end{abstract}

$\mathrm{T}$ HE physician is the final common pathway for nearly all professional decisions about the use of health resources. In the past, it was assumed (or at least hoped) that physicians would make such decisions on the basis of up-to-the-minute familiarity with biomedical science as well as a concern for cost effectiveness that would help protect the patient's or the public's purse. Evidence suggests that this is often not the case; incomplete or outdated medical knowl-

From the Department of Social Medicine and Health Policy and the Division on Aging. Harvard Medical School. Address reprint requests to Dr. Avorn at Harvard Medical School, 643 Huntington Ave., Boston. MA 02115.

Supported by the Division of Extramural Research of the National Center for Health Services Research. scribing of the target drugs by 14 per cent as compared with controls $(P=0.0001)$. A comparable reduction in the number of dollars reimbursed for these drugs was also seen between the two groups, resulting in substantial cost savings. No such change was seen in physicians who received mailed print materials only. The effect persisted for at least nine months after the start of the intervention, and no significant increase in the use of expensive substitute drugs was found. Academically based "detailing" may represent a useful and cost-effective way to improve the quality of drug-therapy decisions and reduce unnecessary expenditures. (N Engl J Med $1983 ; 308: 1457-63$.)

edge and decisions to use unnecessarily costly resources are frequent in day-to-day practice. ${ }^{1-3}$ Regulatory attempts to improve the quality and the economy of medical practice have produced mixed results and have recently been scaled down or dismantled. ${ }^{4}$ Competency requirements for physicians after initial licensure have been unaceptable to the profession and are not likely to become widespread in the foresecable luture." Continuing education through formal courses and journals has an important role, but a relatively small proportion of physicians participate actively in such activities, ${ }^{i}$ and their impact on actual physician performance is controversial. ${ }^{7}$ Even in the alssence of flagrantly poor patient care, small amounts of "slip- 
page" in the quality or cconomy of daily clinical decision making can - when multiplied over millions of patients each day - gencrate substantial morbidity and cost in the aggregate, much of which may well be preventable.

This paper reports on a three-year investigation that was designed to develop ways of improving the accuracy and appropriateness of one aspect of physicians' therapeutic decision making - the prescribing of drugs - in a noncocrcive, nonregulatory way. Principles of communications theory and behavioral science were combined with conventional educational techniques to provide information to physicians about drugs that are often used inappropriately and to replace their use with more rational therapeutic alternatives. The program was implemented and evaluated as a randomized controlled trial.

Less than optimal prescribing decisions by physicians are not uncommon. Drugs that are largely ineffective are used widely ${ }^{8}$; dosages or combinations are often pharmacologically irrational ${ }^{9-11}$; useful older drugs are passed over in favor of newer agents that are no more effective but may be considerably more expensive or toxic. ${ }^{12}$ Our experimental intervention was based on a consideration of the numerous underlying causes of such decisions about drug use. With new agents being introduced into practicc at an unprecedented ratc, it is increasingly difficult for physicians to keep abreast of important developments in pharmacology. Pharmaceutical companies have been quick to fill this educational gap. An average of $\$ 5,000$ per physician per year is spent on a variety of measures designed to acquaint practitioners with specific products and encourage their use. ${ }^{13}$ In these efforts, the companies make expert use of the most effective tools available in generating behavior change: person-toperson contact with practitioners through salespeople ("detailers") who make up in affability, small gifts, and extensive knowledge of sales techniques what they lack in clinical expertise ${ }^{14,15}$; the wide dissemination of visually arresting, persuasive, and emotionally involving print materials; and frequent repetition of messages containing a few basic concepts. The more staid, visually unstimulating format of the medical litcrature itsclf - though replete with data, careful methodology, and references - often fares poorly next to the effective marketing strategies that incvitably surround research findings. ${ }^{16}$

Noncommercial factors also play a large part in encouraging frequent use of certain medications, often beyond the level of clinical appropriateness. Patients frequently demand a prescription, sometimes even stipulating the brand name desired, on the basis of their expectations of the therapeutic encounter or on their reading of the lay media. ${ }^{17}$ Physicians, too, often see the recommendation of a drug (preferably a modcrn one) as a requisite part of their care of the patient or may use the writing of a prescription as an efficient "termination strategy" to indicate to the patient that the visit has been consummated. ${ }^{18}$ Given the interplay of all these forces, it is surprising that irrational prescribing is not even more common than it is.

Viewed as a marketplace transaction, drug prescribing is unlike most other kinds of economic intercourse. The person making the consuming decision (the physician) is different from the payer, who - in the case of third-party reimbursement (as in Medicaid, some health-maintenance organizations, or the Veterans Administration) - may also be different from the actual consumer, who is, of course, the patient. There may be important gaps in the knowledge of the patient or the physician, preventing optimal choices among available products. The federal drugregulatory apparatus is not always able to prevail over special interests in its efforts to remove ineffective agents from the marketplace. ${ }^{8}$

After reviewing the antecedents of and possible remedies for inappropriate drug use, we initiated a randomized controlled trial to study ways to enhance the accuracy of physicians' prescribing decisions. Our hypothesis was that sound data on clinical pharmacology and cost issues could be used to improve such decisions if that information were presented in an educational outreach program that was rooted in established principles of behavioral science, market research, and communications theory.

\section{Methods}

\section{Target Drugs}

On the basis of an analysis of national prescribing practices and evidence from published controlled clinical trials, we chose as targets three drug categories that seemed to reflect less than optimal prescribing of several distinct types: propoxyphene, cerebral and peripheral vasodilators, and cephalexin.

\section{Propoxyphene}

When it was first introduced in the 1950s, propoxyphene (e.g., Lilly's Darvon) was heralded as a potent non-narcotic analgesic that was more effective than over-the-counter analgesics but that lacked the dangers associated with the opiates. The drug, often in combination with aspirin or acetaminophen, rapidly became widely used and was one of the best-selling products in the industry. However, as clinical experience mounted and more careful controlled trials were conducted, it became apparene that the analgesic efficacy of propoxyphene had been overstated. $A$ number of controlled trials showed that propoxyphene was generally inferior to or at best roughly comparable to aspirin or acctaminophen as an analgesic. ${ }^{19,20}$ Increasing evidence of its potential for abuse and its lethality in high doses (or in combination with alcohol) entered the literature. ${ }^{21}$ Although its use has diminished slowly, propoxyphene has remained on the list of the "top 50" drugs prescribed nationally. ${ }^{22}$

\section{Cerebral and Peripheral Vasodilators}

Outdated hypotheses about the causes of senile dementia attributed this condition to inadequate cercbral blood flow. Although this explanation has been discredited, it gave rise to a number of "cerebral vasodilators" that are still currently in wide use for the treatment of mental failure in the elderly. Besides being physiologically irrational, the use of these agents is unlikely to cause any clinically useful dilation of stenotic vessels whose lumens are permanently narrowed by atherosclerotic changes. ${ }^{23}$ In any case, local autoregulation generally causes maximal dilatation of vessels supplying is- 
chemic areas. If they are effective at all, these agents may well dilate the more normal vessels in other vascular beds (such as the gut), thereby decreasing the flow to ischemic areas. ${ }^{2-1}$ Finally, the overwhelming burden of evidence from controlled trials demonstrates that these drugs have little or no use clinically. ${ }^{25}$ Similar arguments apply (o) the drugs (often the same ones) promoled for the treatment of peripheral vascular insufficiency. ${ }^{26}$ During our investigation, the Medicaid programs of several states decided to end reimbursement for most cerebral/peripheral vasodilators, with the exception of papaverine. In one of the states included in our study, such a policy was implemented in the midst of the study. Therefore, before the start of data analysis, papaverine was considered separately and used as a marker for the other vasodilators for which reimbursement was to be curtailed (cyclandelate, nylidrin, and isoxsuprine). Ergofoid mesylates (c.g., Hydergine), which are not vasodilators and which differ in important ways from these drugs, were not considered in this category in any phase of the study.

\section{Cephalexin}

This drug, commonly prescribed as Keflex (Lilly), difiers from the agents in the other two categories in that its efficacy is unquestioned; furthermore, toxicity is not a major problem. However, as a cephalosporin antibiotic, it represents an important problem in drug use: the heavy promotion and extensive use of costly secondgeneration or third-generation antibiotics to replace older drugs that are inexpensive but still effective. ${ }^{12}$ Although the newer ancibiotics clearly offer advantages to certain selected paticnts with respect to their spectrum of activity or side effects, most observers agree that their current use extends well beyond such carefully selected patients, and at considerable cost..$^{27.28}$

\section{Prescribing Data and Sample Selection}

As part of their routine pharmacy-reimbursement activities, the Medicaid programs of many states maintain continuing computerized records of all prescriptions filled by patients in the program. Because self-reporting by physicians is a poor measure of actual prescribing behavior, we used Medicaid prescribing records to document changes in the prescribing of target drugs. Records were obtained of all reimbursed prescriptions from four Medicaid programs with accurate drug-information systems that represented a range of geographic and urban-rural sites (Arkansas, New Hampshire, Vermont, and the District of Columbia). In order to target physicians who in fact prescribed the drug groups in question, we determined how many prescriptions in each drug group were written in 1979 through Medicaid by each physician $(n=5.55 .5)$ in the four study states. Physicians who wrote 20 or more prescriptions per ycar from each of two drug groups or 30 or more prescriptions per year from any one drug group (through Medicaid) were admitted into the sample; this resulted in an initial group of 435 physicians. Regression toward the mean was minimized in all groups by using an entire calendar year of prescribing data to choose the sample.

\section{The Interventions}

Using a randomized controlled design (described below), we allocated physicians to three experimental groups: a control group, a printed-materials-only group, and a face-to-face education group. The control group was exposed to no intervention. The prescribing patterns of this group were recorded to measure any nonexperimental factors (c.g., reports in the medical literature or changes in drugpromotion strategies) that might affect drug prescribing.

'The print-only group received a letter announcing the existence of a pilot drug-information program based at a medical school and designed to provide practicing physicians with information about commonly used pharmaccutical products to help them make optimal drug choices. 'These physicians then received in the mail a series of print materials that we had prepared to simulate (wo commonly used educational approaches. The first was patterned after and closely resembled the FDA Drug Bulletin. It was devoid of any visual or literary interest and cautioned physicians about problems associ- ated with the target drugs in relation to their efficacy, toxicity, or cost. Three separate issues were written and printed; each was mailed twice over a period of four months. The bulletin alone was sent to hall the physicians in the print-only group. The other half of the group were mailed a scries of six "unadvertisements" in addition to the drug bulletins, packaged in a series of cight mailings over a period of four months. These contained the same information as the drug bulletins, but presented in a four-color, profusely illustrated, visually appealing format designed with the help of graphic artists. The information in the "unadvertisements" was prepared in accordance with principles of communications theory and behaviorchange research to intensify its impact. $A$ market-research consultant (Prof. Roberta Clarke) conducted interviews with physicians not included in our study but demographically similar to those who were, to probe their understanding of the target-drug groups and their reasons for using them. The insights gained from these interviews were then incorporated into the educational strategy. Each "unadvertisement" had a large picture and headline on its front side, with a few key clinical facts about the drug in question. On the other side of the sheet, these concepts were elaborated somewhat, with selected research data highlighted in a graphic format. In each case, specific alternatives to the use of the target drugs were presentrd. 'These included the use of less expensive but equally effective prescription drugs (c.g., sulfa instead of cephalexin for uncomplicated urinary-tract infection); the recommendation to patients of overthe-counter preparations (c.g., aspirin or acetaminophen instead of propoxyphene); avoidance of drug therapy altogether (as in viral pharyngitis); behavioral instead of pharmacologic therapy (c.g., exercise for claudication); or a diagnostic mancuver (a workup for dementia instead of the use of cerebral vasodilators). Six to twelve citations of articles from refereed journals were included in each of the six "unadvertisements" for physicians who wanted to learn more about the issues.

To address the perceived problem that patient demand is an important determinant of drug-prescribing patterns, we also prepared four brochures for laypeople that were designed to facilitate the desired changes in drug use. These deale with the high efficacy of aspirin, the uselessness of antibiotics for viral infections, the role of exercise in claudication, and behavioral therapy for the senile patient. Physicians who had been randomly assigned to the "unadvertisement" half of the print-only group were sent single copies of each of these patient-education materials and were given a reply card for ordering copies in bulk at no charge. These mailed materials were sent out between December 1980 and April 1981.

The third group in the study was the face-to-face group. Physicians who were randomized into this category received the same explanation, drug bulletins, "unadvertisements," and patient brochures that were distributed to members of the print-only group. In addition, two visits to these physicians were scheduled by pharmaceutical educators who were specially trained by us in the pharmacology of the drugs under discussion as well as in communications techniques. Six of these were clinical pharmacists who held the Pharm.D. degree, and one was a pharmacologist. All worked in the same geographic region as the physicians they visited. Upon receiving the names of physicians in the face-to-face group, the "detailing" personnel telephoned their assigned physicians and arranged to visit the practitioner's office at a mutually convenient tine. During the meeting, they explained that the visit was part of an experimental program to provide physicians with up-to-date, unbiased information about commonly used drugs to help them improve their decisions about drug prescribing. The pharmacists then reviewed the information in the print materials and encouraged the physicians to modify their prescribing practices in the direction of more restrained use of the target drugs. Several general principles of education and behavior change ${ }^{29-31}$ were included in the training sessions of the "detail" personnel. Strong appeals based on fear were avoided; improvement of the therapy of clinical problems commonly seen by the physicians was generally emphasized above cost considerations. Both sides of controversial issues were presented before recommendations were made. Main points were communicated succinctly and graphically, and the discussion stressed the evaluation of published data from randomized controlled trials; the physi- 
cians were encouraged to participate in the educational exchange and to discuss specific problem cases. Bulk copics of the patienteducation materials were left with the physicians, as were single additional copies of the other print materials that had been mailed previously. These visits occurred during the first six months of 1981 .

\section{Randomization}

Because of the potential impact on prescribing of differences in geographic location, variations in Medicaid-program rcimbursement, and urban-rural differences, we implemented a randomized block design. All 435 study subjects were subdivided into 12 homogeneous blocks. Each block included physicians who were residing in the same state (or the District of Columbia) and in towns with comparable numbers of physicians. Control and experimental interventions (described above) were then allocated randomly within each block, thus increasing the precision of the overall comparisons. Extensive earlier work on patterns of communication among physicians about drug use documented the existence of important networks of mutual influence within specific geographic areas, particularly small towns. ${ }^{32}$ If a small town contained more than one physician from our sample, all physicians in that town were randomized as a cluster to prevent cross-contamination of information among experimental groups. 'This prevented a situation in which two or three physicians working together, yet assigned to different experimental groups, might share the educational information they received with one another.

\section{Statistical Analysis}

To determine the effects of the educational interventions, all Medicaid data on drug use for the period from January 1980 to December 1981 were transmitted to us by the four state Medicaid programs. Data on the numbers of dollars spent and units prescribed as well as on the numbers of patients receiving drugs from the three target drug groups were extracted and aggregated by individual physician-code numbers. We controlled for seasonal variations in prescribing (particularly for the antibiotic category) by comparing postintervention outcomes with those of the same period in 1980 (preintervention). Data were also collected on possible substitute drugs that might have been used by the physicians to replace the target drugs (c.g., nonsteroidal anti-inflammatory agents instead of propoxyphene).

In addition to this information, data on age, specialty, and board certification were collected from published listings and local medical-society records. The pharmacist-educators also made detailed quantitative and subjective records describing the visits immediately after each attempled encounter. These included waiting times, time spent on each drug with the physicians, frequency of and reasons for refusals, and assessments of the level of involvement and receptivity of physicians.

The following simple multiple-regression model was employed to determine the size and significance of the eflect of each educational intervention on prescribing:

UNITS $_{\text {pist }}=$ UNITS $_{\text {pre }}+$ PRINT-ONLY + FACE-TO-FACE.

In this model, an indicator variable ( 0 or 1) was used to represent membership in an experimental group for each physician. 'The model thus controlled for differences in preintervention prescribing levels among individual physicians as well as for prescribing trends within the control group. This made it possible to measure the independent effect of each intervention, controlling for differences in prior drug use as well as for changes in prescribing that were unrelated to the intervention, as reflected in control-group drug use.

\section{Substitution Effects}

The effect of any intervention aimed at changing behavior can be seriously undermined if one kind of inappropriate activity replaces another. In addition, the cost-containing effect of this program would be quite different if, for example, propoxyphene were replaced with an expensive nonsteroidal anti-inflammatory drug rather than with aspirin, even though both changes would produce satisfactory clinical results. For these reasons, Medicaid prescribing data were also recorded for a wide variety of alternative drugs (described below) that might conceivably have been used to replace the target drugs.

\section{Results}

The physicians in each of the study groups were comparable before the intervention in terms of the amount of the target drugs they prescribed through Medicaid, their type of specialty, and their board certification. Physicians in the initial sample were closely followed to document the frequency of drop-outs equally in all three groups before any intervention. Of the original 435 members of the sample, 9 had moved out of the state, 6 had died, and 5 had retired by the start of 1981. The dropout rates for each cause were found to be approximately equally divided among the three study groups.

Of the practicing physicians who were randomly assigned to the face-to-face group, 92 per cent consented to meet with our educational representatives. Of these, 81 per cent met for the scheduled two visits, and 19 per cent for only one visit. In all drug-use analyses, all physicians who were assigned to the facc-to-face group are considered, whether or not they agreed to participate in the educational program.

\section{Impact on Prescribing of All Target Drugs}

The upper section of Table 1 presents the basic summary data on mean changes in the prescribing of target drugs according to experimental group. A significant difference was found in the postintervention prescribing patterns of the face-to-face group as compared with those of the other physicians in the study.

Table 1. Effect of Educational Program on Prescribing According to Drug Category and Experimental Group.*

\begin{tabular}{|c|c|c|c|c|}
\hline & \multicolumn{2}{|c|}{$\begin{array}{c}\text { ME:AN No. OF } \\
\text { UNITS PRI:SCRIBEII }\end{array}$} & \multicolumn{2}{|c|}{ Progikam Elaj:cts ${ }^{\dagger}$} \\
\hline & $\begin{array}{c}\text { BEFOKE: } \\
\text { INTERVENTION } \\
\text { (MAR.-NOV. 1980) }\end{array}$ & $\begin{array}{c}\text { AFTI:R } \\
\text { INTERVI:NIION } \\
\text { (MAR.-NOV. 1981) }\end{array}$ & $\begin{array}{l}\text { ME:AN DIFFERENCISS } \\
\text { IROM (ONTROI. } \\
\text { CIROUIP }\end{array}$ & $\underset{\text { VAIUES }}{P}$ \\
\hline \multicolumn{5}{|l|}{ All three drugs } \\
\hline Control & 5415 & 4921 & - & - \\
\hline Print only & 5875 & 5071 & -251 & NS \\
\hline Face-to-face & 5439 & 4174 & -782 & 0.00001 \\
\hline \multicolumn{5}{|l|}{ Cephalexin } \\
\hline Control & 1101 & 1240 & - & - \\
\hline Print only & 1403 & 1434 & -100 & NS \\
\hline Face-to-face & 1272 & 1029 & -382 & 0.0006 \\
\hline \multicolumn{5}{|l|}{ Propoxyphene } \\
\hline Control & 3060 & 2626 & - & - \\
\hline Print only & 3216 & 268.3 & -64 & NS \\
\hline Face-to-face & 2743 & 2125 & -2.32 & 0.04 \\
\hline \multicolumn{5}{|l|}{ Papaverine } \\
\hline Control & 1254 & 1055 & - & - \\
\hline Print only & 1256 & 953 & -104 & NS \\
\hline Face-to-face & 1424 & 1020 & -176 & 0.02 \\
\hline
\end{tabular}

*N equaled 140 for the control group, 132 for the print-only group, and 141 for the face-(o) face group.

tP values and mean differences from controls were calculated by means of the multiple regression model described in the text, which controlled for preintervention differences in individual physician prescribing as well as for prescribing trends among control physicians during the study. All P values are one-tailed. 
In terms of units of medication (number of tablets or capsules) prescribed for the three target-drug groups (with papaverine the only constantly reimbursed member of the vasodilator group), physicians in the face-to-face group prescribed an average of 782 units per physician fewer than did control physicians in the nine months during and after the intervention, after we controlled for the levels of prescribing in the nine months before the intervention $(\mathrm{P}=0.0001)$. (In this and all other calculations, $P$ values represent the significance of the difference between the controls and the face-t()-facc group in the regression equation described above.) Time-series analysis revealed that this difference was significant by the end of the first quarter during which the physician-education visits occurred. The differences in prescribing remained highly significant, with no sign of diminution in effect nine months after the start of the office-based intervention - the latest period for which data are available.

No statistically significant effect was found for the print-only group. Furthermore, when this group was divided into its constituent halves (drug bulletin alone vs. all print materials), no reliable effect on prescribing was seen for either subgroup. Prescribing levels for 1981 are generally lower than those for 1980 in all groups - a difference that is possibly related to the imposition of caps on drug reimbursement by two of the states included in the study. However, the even distribution of experimental groups among all states prevented these policy changes from biasing our findings.

\section{Impact on Prescribing of Individual Drugs}

'Table 1 also presents data on changes in the prescription of individual drugs by each experimental group. For cephalexin, physicians in the face-to-face group prescribed an average of 382 units fewer than control physicians (whose prescribing of this drug was on the increase) during and after the intervention period $(P=0.0006)$. For propoxyphene and papaverine, physicians in the face-to-face group prescribed 232 and 176 fewer units, respectively, as compared with controls $(P=0.04$ and 0.02$)$.

\section{Substitution Effects}

The recommended alternatives to each of the target drugs were in all instances relatively inexpensive: for propoxyphene, aspirin or acetaminophen; for the papaverine-type "vasodilators," mild exercise (for claudication) or no drugs at all; for cephalexin, a conventional, less expensive antibiotic such as sulfa or ampicillin (for urinary-tract infection), penicillin (for streptococcal pharyngitis), or no antibiotic at all (for viral symptoms). Particular attention was therefore paid to the use by all experimental groups of other, more costly substitute drugs that physicians may have independently chosen to replace the target drugs. These were the nonsteroidal anti-inflammatory drugs or pentazocine (to replace propoxyphene); ergoloid mesylates (c.g., Hydergine) to replace the papaverine- like "cerebral vasodilators"; and other oral cephalosporins or trimethoprim-sulfamethoxazole to replace cephalexin. No trend was found to indicate any increased use of these nonrecommended alternative drug catcgories in the face-to-face group of physicians as compared with the controls, with no corresponding increase in costly substitute drugs. As expected, a small increase was seen in the face-to-face group in recommendations for over-the-counter analgesics such as aspirin or acetaminophen products in those states for which Medicaid reimburses for such products. However, this difference did not reach statistical significance, and its magnitude was small.

\section{Cost Savings}

For the nine-month period that included and followed the educational intervention, the face-toface intervention caused an average decrease in prescribing costs of $\$ 105$ per physician for the three target-drug groups, in comparison to controls $(P=0.002)$. As noted above, no decrease over time was seen in the effects of the program during this period. Making the conservative assumption that the observed effect persisted for another three months and then completely disappeared, the annual savings to the Medicaid program alone from this small pilot program amounted to $\$ 19,740$ for the 141 physicians in the face-to-face education group. At a projected total program cost (based on our experience) of approximately $\$ 100$ per physician to conduct such an intervention, it is likely that this approach could generate savings at least equal to its costs, even if one considers only the savings realized within the Medicaid program alone. Additional nonquantified benefits, such as improved quality of care or decreased drug expenses incurred by patients or other third-party payers, would improve this benefit-cost relation still further.

\section{Discussion}

This study represents a large-scale randomized controlled experiment to test personal as opposed to printbased methods of improving the appropriateness of clinical decision making in ambulatory care. It indicates that face-to-face education of the practicing physician is an effective means of reducing less than optimal prescribing decisions and that such an approach can generate important changes in the nature and cost of drug use. These findings are consistent with those from other research on inducing bchavior change, in areas ranging from smoking ${ }^{33}$ to patient compliance. ${ }^{3.1}$ It should be noted that physicians in the program were approached as participants in an innovative demonstration program rather than as "mis-prescribcrs." $\Lambda$ s a result, it is unlikely that Hawthorne-type effects accounted for the prescribing changes observed. Although physicians were admitted to the sample on the basis of frequent use of one or more study drugs through their Medicaid practices, these lindings are readily generalizable to other physicians 
for several reasons. First of all, many of the physicians studied simply had large Medicaid practices and were in fact only moderate users of the target drugs. Secondly, since entry into the sample required frequent use of only one or two of the drug groups studied, most physicians in the sample used only moderate amounts of the other study drugs, providing useful information on the effect of such a program on moderate-to-low levels of prescribing. No clear difference was seen in the effect of the program for high-use versus low-use drugs, suggesting that this approach can be equally effective for wide ranges of target-drug use. The failure of the print-only intervention to bring about change may also be explained in part by the fact that many physicians did not recall secing the materials at all. Several reported that our materials looked so much like drug-company advertisements that they were probably thrown out by secretaries who had standing orders to discard unopened all drug-promotional literature upon receipt.

One recent review of health-care cost-containment research concluded that financial rewards or penalties are often necessary to induce physicians to practice more cost-effective care. ${ }^{35}$ By contrast, our data demonstrate that innovative in-person education can improve practice without the use of economic incentives. Luft's review of the performance of health-maintenance organizations also indicates that physicians in prepaid group practices do not scem to alter their use of medical technology as a result of financial incentives alone. ${ }^{36}$

The results confirm the concept that office-based physicians welcome practical and unbiased drug information. All but 8 per cent of this randomly selected physician population agreed to participate in the faceto-face educational encounters; many specifically requested additional new drug information as soon as it became available. One advantage that a drug-information program based at a medical school has over the standard commercial promotional channels is that cost considerations and information about adverse effects are more likely to be given prominence in materials prepared by nonindustry sources. ${ }^{37}$ In contrast, one study of traditional continuing-education courses found that only 7 per cent of the state's physicians accounted for half of all physician-hours of attendance. ${ }^{6}$ Targeting educational efforts to those who can benefit from them most and then delivering the messages to the physician's doorstep appear to be a more effective approach to the continuing education of busy office practitioners.

Of course, this approach is only one of several possible ways to improve the quality and efficiency of drug use. For years, hospitals have removed from their formularies drugs that were thought to be unsafe, ineffective, or unnecessarily costly. More recently, several state Medicaid programs have done likewise, refusing to reimburse pharmacists for dispensing such drugs. In fact, in some states this approach has been taken for two of the drug groups we studied - propoxyphene and the "cerebral vasodilators." We concur in general with such an approach, but we note two limitations. The first is that the denial of reimbursement for specific drugs, even when it is based on sound data, usually mects with a storm of protest from physicians and the drug industry - a fact that probably explains its relatively limited application thus far. Secondly, there are many drugs (cephalexin is an example in the current study) that are quite safe and effective but that are often used far in excess of their specific indications. Education rather than restriction is necessary for this large group of agents - a perspective that has been advanced by the Pharmaceutical Manufacturers Association as well. ${ }^{38}$

Continuing feedback from drug-use audits is another approach that has met with some success in ambulatory settings ${ }^{39,41}$; however, this method has been most effective in reducing errors of omission, identified on the basis of agreed-on standards of care. In addition, positive effects seem to diminish rapidly after the discontinuation of such fecdback.

Several authors ${ }^{11,42}$ have speculated that one or more impartial, university-based sources of drug information could perform an important service by disseminating such information on a wide scale, comparable to that of pharmaceutical advertising. However, the financing of such an endcavor has been problematical. Cost data from our work suggest that the savings in reduced drug expenditures within the Medicaid program alone might approximate the cost of conducting such a program on an operational basis. It is important to note that Medicaid prescribing data were used only as an indicator of the changes in prescribing practices that resulted from the experimental intervention. Obviously, a much larger fraction of prescribing volume occurs in the private, noncomputerized sector of practice. Since the educational program did not address Medicaid practice in particular, it is likely that the changes that were seen in Medicaid prescribing were replicated in private prescribing as well. In the case of cost-related educational messages, the magnitude of changes in prescribing for self-paying patients may even have been greater.

If these results can be replicated over time for other drugs and in other settings, such reductions in cost and potential improvements in care may make this kind of drug-education program economically self-sustaining in a variety of contexts. 'These would include any health-carc delivery systems in which the program covers the cost of drugs, such as Medicaid, several health-maintenance organizations, and the Veterans Administration. Further work will also be needed to determine whether face-to-face continuing education (suitably modified) can be useful in improving the appropriateness of other clinical decisions, such as the ordering of diagnostic studies, referral to specialists, or admission of patients to hospitals or long-term-care facilitics. In a time of constricting budgets and increasingly expensive care, such an approach, which holds the promise of improved practice coupled with cost containment, is a subject worthy of further investigation. 
We are indebted to the following colleagues for their collaboration in the role of drug-information specialists: Latwrence Robinson, Pharm.D., Maude Babington, Pharm.D., and Dan Spadaro, Pharm.D. (University of Arkansas); Donald Fraser, Pharm.D. (Massachusetts College of Pharmacy); Richard Deth, Ph.D)., (Northeastern University); and Aida I.eRoy, Pharm.I)., and Nancy MacArthur, Pharm.D. (Health Information Designs, Inc.); to Dennis Lyons, Larry Pahigan, and Michael Levy of Programs and Analysis, of Burlington, Mass., for their invaluable help in the analysis of the prescribing data described in this study; (o) Demnis RossDegnan and Karl Finison for programming and statistical work; to Susan lewis for important technical assistance; to Roberta Clarke, D.B.A., and Howard Silk (Boston University), Lee Morse (Health Information Designs), and Heistand Design, Inc., for assistance in the design of the intervention; and to the officers and staff of the Medicaid programs of Arkansas, New Hampshire, Vermont, and the District of Columbia, without whose cooperation this work would not have been possible.

\section{REFERENCES}

1. Cochrane AL. Effectiveness and efficiency: random reflections on health services. London: Nuffield Provincial Hospitals Trust, 1972.

2. Bunker JP, Barnes BA. Mosieller F, eds. Costs, risks, and benefits of surgery. New York: Oxford University Press, 1977.

3. Hiatt H. Protecting the medical commons: who is responsible? N Engl J Med $1975 ; 293: 235-41$.

4. Smits HL. The PSRO in perspective. N Engl J Med 1981: 305:253-9.

5. Freidson E. Professional dominance; the social structure of medical care. New York: Atherton Press, 1970.

6. Lewis CE, Hassanein RS. Continuing medical education - an epidemiologic evaluation. N Engl J Med 1970; 282:254-9.

7. Greene R, Simmons J. Improving physician performance. In: Greene R, ed. Assuring quality in medical care: the state of the art. Cambridge, Mass.: Ballinger, 1976:173-89.

8. Temin $P$. Taking your medicine: drug regulation in the United States. Cambridge, Mass.: Harvard University Press, 1980.

9. Castle M, Wilfert CM, Cate TR. Osterhout S. Antibiotic use at Duke University Medical Center. JAMA 1977; 237:2819-22.

10. Scheckler WE, Bennett JV. Antibiotic usage in seven community hospitals. JAMA 1970; 213:264-7.

11. Stewart RB, Cluff LE, Philp JR, eds. Drug monitoring: a requirement for responsible drug use. Baltimore: Williams \& Wilkins, 1977

12. Maugh TH II. A new wave of antibiotics builds. Science 1981: 214:1225-8.

13. Silverman M, Lec PR. Pills, profits, and politics. Berkeley, Calif.: University of California Press, 1974:54-7.

14. Hemminki E. Content analysis of drug detailing by pharmaceutical representatives. Med Educ 1977; 11:210-5.

15. Smith MC. Principles of pharmaceutical marketing. Philadelphia: Lea \& Febiger, 1975

16. Avorn J, Chen M, Hartley R. Scientific versus commercial sources of influence on the prescribing behavior of physicians. Am J Med 1982; 73:4-8.

17. Hall D. Prescribing as social exchange. In: Mapes R, ed. Prescribing practice and drug usage. London: Croom Helm, 1980:39-57.
18. Heath $C$. On prescription-writing in social interaction. In: Mapes $R$, ed Prescribing practice and drug usage. London: Croom Helm, 1980:58-69.

19. Miller RR. Propoxyphene: a review. In: Miller RR, Greenblatt D, eds. Drug therapy reviews. Vol 2. New York: Elsevier, 1979:218-57.

20. Mocrtel CG, Ahenann DL. Taylor WF, Schwartau N. A comparative evaluation of marketed analgesic drugs. N Engl J Med 1972: 286:813-5.

21. Tennant FS Jr. Drug abuse in the U.S. Army. Europe. JAMA 1972: 221:1146-9.

22. United States National Center for Health Statistics. Drugs most frequently used in office-based practice: National Ambulatory Medical Care Survey, 1980. Hyattsville, Md.: National Center for Health Statistics, 1982. (Advance data from vital and health statistics. No. 78) (DHHS publication no. (PHS)82-1250).

23. American Medical Association. AMA drug evaluations. 4th ed. New York: John Wilcy, 1980:214-5.

24. Necdleman P. Johnson EM Jr. Vasodilators and the treatment of angina. In: Gilman AG. Goodman LS. Gilman A, cds. The pharmacological basis of therapeutics. 6th ed. New York: Macmillan, 1980:819-33

25. Yesavage JA, Tinklenberg JR. Hollister LE, Berger PA. Vasodilators in senile dementias: a review of the literature. Arch Gen Psychiatry 1979; 36:220-3.

26. Coffman JD. Vasodilator drugs in peripheral vascular disease. $\mathrm{N}$ Engl J Med 1979; 300:713-7.

27. Kunin CM, Tupasi T, Craig WA. Use of antibiotics: a brief exposition of the problem and some tentative solutions. Ann Intern Med 1973: 79:55.560.

28. Noel MW, Paxinos J. Cephalosporins: use review and cost analysis. Am J Hosp Pharm 1978; 35:933-5.

29. Karlins M, Abclson HI. Persuasion: how opinions and attitudes are changed. 2 d ed. New York: Springer, 1970.

30. Hovland $\mathrm{Cl}$, Lumsdaine AA, Sheffield $\mathrm{FD}$. Experinents on mass communication. Princeton. N.J.: Princeton University Press, 1949.

31. Watts WA. Relative persistence of opinion change induced by active compared to passive participation. J Pcrs Soc Psychol 1967; 5:4-15

32. Coleman JS, Katz E, Menzel H. Medical innovation: a diffusion study. Indianapolis: Bobbs-Merrill, 1966.

33. Leventhal H. Cleary PD. The smoking problem: a review of the research and theory in behavioral risk modification. Psychol Bull 1980; 88:370-405.

34. Sackett DL. Haynes RB, eds. Compliance with therapeutic regimens. Baltimore: Johns Hopkins University Press, 1976.

35. Eisenberg JM. Williams SV. Cost containment and changing physicians' practice behavior: can the fox learn to guard the chicken coop? JAMA 1981; 246:2195-201.

36. Luft HS. Assessing the evidence on HMO performance. Milbank Mem Fund Q 1980; 58:501-36.

37. "Opren scandal." Lancet 1983; 1:219-20.

38. Prescription drug coverage within publicly financed health insurance programs. Washington, D.C.: Pharmaceutical Manufacturers' Association. 1983.

39. McDonald CJ. Protocol-based computer reminders, the quality of care and the non-perfectability of man. N Engl J Med 1976; 295:1351-5.

40. Bamett GO, Winickoff R. Dorsey JL. Morgan MM, Luric RS. Quality assurance through automated monitoring and concurrent feedback using a computer-based medical information system. Med Care 1978: 16:962-70.

41. Rucker TD. Drug information for prescribers and dispensers: toward a model system. Med Care 1976; 14:156-6.5.

42. Cluff $\mathrm{L}$. The prescribing habits of physicians. Hosp Prac 1967; 2(9):100-4 